\title{
RETRACTI ON
}

http://dx.doi.org/10.1590/1678-77572016retr001

The Editorial Board of the Journal Applied Oral Science communicates the formal retraction of the manuscript:

Alvarez C, Benítez A, Rojas L, Pujol M, Carvajal P, Díaz-Zúñiga, et al. Differential expression of CC chemokines (CCLs) and receptors (CCRs) by human T lymphocytes in response to diferente Aggregatibacter actinomycetemcomitans serotypes. J Appl Oral Sci. 2015;23(6):580-90. http://dx.doi.org/10.1590/1678775720150285

Since it comprises a duplicated version of a manuscript previously published in the preceding edition of the J ournal Applied Oral Science:

Alvarez C, Benítez A, Rojas L, Pujol M, Carvajal P, Díaz-Zúñiga, et al. Differential expression of CC chemokines (CCLs) and receptors (CCRs) by human T lymphocytes in response to diferente Aggregatibacter actinomycetemcomitans serotypes. J App. Oral Sci. 2015;23(5):536-46. http://dx.doi.org/10.1590/1678775720150285

Prof. Dr. Gustavo Pompermeier Garlet

Editor-in-Chief 